\title{
FELIPE CALDERÓN O EL INFORTUNIO DE UNA TRANSICIÓN
}

\author{
LOREnZo Meyer
}

\section{LO QUE ESTUVO EN JUEGO}

Para adentrarse en Un PROceso político contemporáneo, un buen inicio son sus antecedentes, el examen de los hechos más significativos que le precedieron. Por tanto, un juicio sobre la esencia y el significado político del sexenio que presidió Felipe de Jesús Calderón Hinojosa (2006-2012) tiene que empezar por echar una mirada a la naturaleza del entorno en que surgió: el inicio de lo que se vio como la transición democrática de México.

El examen del tiempo político inmediatamente anterior a la presidencia de Calderón puede llevar a concluir que lo ocurrido a partir de 2006 fue una oportunidad desperdiciada para ahondar en la democratización y modernización del régimen político mexicano de manera pacífica, apegada a derecho, con la participación y aquiescencia de la mayoría ciudadana. Y es que, en conjunto, las condiciones que precedieron y permitieron el ascenso de Calderón y su grupo a la presidencia habían estado ausentes desde que México inició su vida como Estado nación independiente. Por tanto, al abrirse la etapa electoral de 2006 el espacio democrático ganado hasta entonces no era aún muy firme pero sí prometedor, conque en esa coyuntura la principal tarea y responsabilidad del gobierno, de cualquier gobierno, debería haber sido consolidar ese espacio. Sin embargo, el segundo presidente panista tomó una serie de decisiones que terminaron por desperdiciar lo tan duramente ganado. Lo que es más grave, a partir de 2006 no sólo no se profundizó el cambio iniciado en el sexenio anterior, 
sino que, como sugieren los teóricos de las transiciones democráticas actuales, si una vez iniciado el proceso de consolidación éste no sigue avanzando a buen paso y no genera más apoyo tanto entre las élites como entre las masas, entonces se corre el riesgo de que surjan patologías, dinámicas que desemboquen en una regresión. ${ }^{1}$

Por su forma y contenido, la elección presidencial de 2006 no ayudó a solidificar la confianza ciudadana que había empezado a emerger seis años antes. ${ }^{2}$ La forma y el contenido del ejercicio mismo del poder de la presidencia de Calderón llevó a que en diciembre de 2012 el poder ejecutivo volviera a quedar en manos del viejo partido autoritario -el PRI-, partido que apenas doce años antes parecía destinado a ser parte de la historia y no del futuro de México. Además, la añeja desconfianza de la ciudadanía mexicana en los comicios y en sus resultados volvió a surgir. ${ }^{3}$

Visto el ciclo calderonista a partir de su conclusión, resulta que el trasfondo de todo el proceso político del periodo fue la persistencia y la agudización de las confrontaciones entre las agendas y proyectos de los actores que hasta entonces habían desempeñado los papeles estelares del proceso de cambio y de resistencia en la transformación del régimen. Ya en 1989 el PRI había perdido el monopolio sobre los gobiernos estatales; de entonces al año 2000, hubo una quincena de gobernadores no priistas. ${ }^{4}$ Además, en 1997, tras 68 años de control ininterrumpido del Congreso por el PRI, la oposición logró la mayoría en la Cámara de Diputados y el pluralismo político empezó a ser una realidad. ${ }^{5}$ Sin

${ }^{1}$ Larry Diamond, Developing Democracy: Toward Consolidation, Baltimore, Johns Hopkins University Press, 1999, p. 64.

${ }^{2}$ Una encuesta de la época dio por resultado que $46 \%$ de los encuestados en una muestra representativa dijeron tener razones para dudar de los resultados oficiales de la elección de 2006 (Alejandro Moreno, "La desconfianza electoral en México", Este País, marzo de 2014, p. 11).

${ }^{3}$ Para 2012, y según la fuente anterior, la proporción de encuestados que pusieron en duda la veracidad de los resultados electorales, aumentó a $51 \%$.

${ }^{4}$ Magali Modoux, "Geografía de la gobernanza. ¿La alternancia partidaria como factor de consolidación del poder de los gobernadores en el escenario nacional?”, Foro Internacional, vol. 46, núm. 3, 2006, pp. 516-519.

${ }^{5}$ Los análisis del sistema presidencialista y de partido de Estado en el México 
embargo, las resistencias al esfuerzo por transformar en democrático el sistema que se había consolidado a partir del triunfo de la Revolución mexicana en 1917, resultaron más fuertes de lo que habían supuesto aquellos optimistas que impulsaron o apoyaron el cambio. En fin, entre la segunda parte del gobierno de Vicente Fox y el final del de Calderón, la transición democrática mexicana se desvió y la naturaleza misma del régimen quedó en entredicho.

El juicio anterior -que no es compartido por todos los observadores del periodo, pues hay quienes consideran al calderonismo como parte del proceso de consolidación democrática que aún sigue en marcha en México ${ }^{6}$ - es el telón de fondo de este análisis, que procederá a examinar someramente los procesos políticos más relevantes del sexenio: la campaña electoral de 2006, la naturaleza de la "guerra contra el narcotráfico" del gobierno contra el crimen organizado y el consecuente aumento de la inseguridad, la creciente importancia de un pluralismo no necesariamente de carácter democrático pues lo protagonizan los poderes fácticos -las grandes concentraciones de poder económico y sindical-y ciertos feudos estatales, la partidocracia -la autonomía de los intereses de las oligarquías que controlaban a los tres grandes partidos-, la relación con Estados Unidos, los efectos de su crisis financiera y la recesión de la economía mexicana y la persistencia de la corrupción.

\section{LA ELECCIÓN DE 2006}

Como ya se apuntó, las elecciones que tras 71 años consecutivos sacaron al PRI de la casa presidencial de Los Pinos, fueron vistas por muchos como un punto de inflexión histórico en el proceso

del siglo xx son numerosos, pero el clásico es el de Pablo González Casanova, $L a$ democracia en México, México, Era, 1965.

${ }^{6}$ Una visión general y diferente de la que se presenta aquí, positiva, en torno a la naturaleza del proceso político mexicano y publicada a mediados y al final del sexenio de Calderón, se tiene en estos dos libros de Héctor Aguilar Camín y Jorge G. Castañeda, Un futuro para México, México, Punto de Lectura, 2009; y Una agenda para México, México, Punto de Lectura, 2012. 
político mexicano. Por primera vez se había celebrado una elección presidencial en condiciones óptimas, pues a la ciudadanía se le presentaron opciones significativas -tres candidatos con proyectos relativamente diferentes-, el ambiente no fue de temor sino de clamor por el cambio, el aparato estatal ya no pudo sesgarse demasiado en favor del candidato oficial, la información difundida por los medios resultó menos inequitativa que en el pasado, hubo observadores externos efectivamente imparciales y la institución encargada de vigilar el proceso y contar los votos fue confiable. ${ }^{7} \mathrm{La}$ elección de 2006 ya no mantuvo esas características.

La sucesión de Vicente Fox fue precedida de una campaña extraordinariamente reñida y de un ambiente dominado por la desconfianza, el encono o el miedo. El viejo partido de Estado, el PRI, apareció como un partido fracturado cuyo candidato, Roberto Madrazo, no concitó el apoyo real de sus propios cuadros y menos el de la ciudadanía. Pronto quedó claro que en esas condiciones a lo más que el PRI podía aspirar era a sobrevivir como tercera fuerza. Desde 2004 Calderón, un panista histórico, inició su precampaña pese a no contar con el beneplácito de Fox. Sin embargo, a inicios de 2005 Fox decidió, con el respaldo en el Congreso del PAN y el PRI, intentar eliminar como candidato a quien aparecía como el verdadero rival de Calderón: Andrés Manuel López Obrador. La vía que Fox eligió para su propósito fue proponer y conseguir que la mayoría del Congreso aprobara el desafuero de López Obrador y cortar de tajo sus aspiraciones electorales. ${ }^{8}$ Sin embargo, una movilización oportuna y espectacular de la izquierda en contra de esa maniobra en abril de 2005 obligó al gobierno

${ }^{7}$ Un estudio breve y sustantivo sobre el proceso electoral del año 2000 se encuentra en José Woldenberg, Historia mínima de la transición democrática en México, México, El Colegio de México, 2012.

${ }^{8}$ La supuesta razón del desafuero fue que no se respetó un amparo en favor del dueño de un predio que se pretendió expropiar para abrir una calle que facilitara llegar a un hospital, cuando López Obrador era aún jefe de gobierno de la capital. Legalmente, el desafuero le hubiera impedido al político tabasqueño registrarse como candidato presidencial; sin López Obrador, las posibilidades electorales de la izquierda en 2006 disminuían mucho. Véase Angélica Cuéllar y Roberto Oseguera, El desafuero de Andrés Manuel López Obrador, México, Guernika, 2011. 
federal a recular, a desistir del desafuero y a cambiar al procurador de la República. A partir de entonces la única y verdadera contienda fue ya entre López Obrador por la izquierda y Felipe Calderón por la derecha. El PRI resultó irrelevante. Formalmente también contendieron otros dos candidatos que parecieron electoralmente insignificantes, aunque finalmente no lo fueron por lo extraordinariamente ajustado del resultado final de la elección, pues la diferencia en votos por Calderón y López Obrador fue de medio por ciento. Así, 3.64\% de los sufragios para los candidatos simbólicos, Patricia Mercado y Roberto Campa, pudo ser decisivo, dependiendo de a cuál de las dos opciones reales le restaron más votos.

Hasta abril de 2006, las preferencias electorales favorecían abiertamente a López Obrador, ${ }^{9}$ pero a partir de esa fecha la situación empezó a revertirse por una serie de errores del puntero y por una campaña electoral bien llevada de parte de Calderón. Éste mezcló de manera muy efectiva propuestas positivas y miedos, pues apelaba a viejos temores contra la izquierda arraigados durante la Guerra Fría mas actualizados al ligar a López Obrador con la figura del presidente de Venezuela Hugo Chávez, con el populismo y difundir spots muy efectivos, como el de "López Obrador, un peligro para México". ${ }^{10}$

Tras la elección, oficialmente ganada por Calderón con un margen de apenas $0.56 \%$, la izquierda se negó a reconocer la legitimidad del resultado y de la nueva presidencia. ${ }^{11}$ Para cuando Calderón dejó el poder, sólo una mayoría relativa de los ciudadanos -34\% - consideraba que México era efectivamente una democracia en tanto que $31 \%$ negaba esa posibilidad y otro tercio (33\%) definía al país como parcialmente democrático. ${ }^{12}$

${ }^{9}$ El periódico Reforma, en una encuesta levantada el 15 de enero de 2006, le daba a López Obrador $40 \%$ de la preferencia, a Calderón 30\% y a Madrazo $26 \%$.

${ }^{10}$ Ese anuncio fue retirado en abril de 2006, pero para entonces ya había conseguido el efecto que buscaba.

${ }^{11} \mathrm{La}$ exposición de las razones del candidato del PRD para no reconocer la legitimidad del triunfo de Calderón la expuso el propio Andrés Manuel López Obrador en su libro, La mafia nos robó la presidencia, México, Grijalbo, 2007.

${ }^{12}$ Fuente: Secretaría de Gobernación, Encuesta nacional sobre cultura política y prácticas ciudadanas, ENCUP, 2012, http://www.encup.gob.mx 
En virtud de lo anterior, desde la perspectiva de una corriente de análisis, y pese a reconocer las fallas y contradicciones de un proceso que obligó en 2007 a reformar el código electoral como resultado de las fallas del año anterior, ${ }^{13}$ la transición democrática mexicana ya había tenido lugar, y durante la presidencia de Calderón, aunque con fallas y problemas, siguió afianzándose. ${ }^{14}$ En contraste, otra perspectiva consideró que en ese segundo sexenio panista el sentido mismo de la transición se desvirtuó al punto que en 2012 el viejo partido autoritario -el PRI- pudo recuperar la presidencia, y que, por tanto, no era posible precisar con exactitud la naturaleza del sistema político mexicano en esa coyuntura ni pronosticar si el impulso democratizador podría recuperar fuerza o si el país derivaría hacia un sistema político híbrido donde se combinasen de manera inestable los elementos democráticos recién adquiridos con rasgos importantes del viejo autoritarismo que nunca se habían ido o que habían reaparecido. ${ }^{15}$ Finalmente, también se abría la posibilidad más peligrosa, la apuntada por la teoría de la transición a la que ya se hizo referencia: la de una regresión autoritaria. ${ }^{16}$

${ }^{13}$ Edmundo Carlos Rodríguez Hernández, "La reforma constitucional electoral 2007 en México", http://www.juridicas.unam.mx/publica/librev/rev/sufragio/cont/1/ens/ens11.pdf

${ }^{14}$ Véase la nota 6. Para José Woldenberg, la transición democrática en México ya es un hecho y el sistema autoritario ya había sido definitivamente desmontado. Desde su perspectiva, el problema residía en que al final del gobierno de Felipe Calderón e inicio del de Enrique Peña Nieto, la calidad de la democracia mexicana era baja. "Los déficits de la transición democrática”, en José Ramón Cossío y Enrique Florescano (coords.), La perspectiva mexicana en el siglo XXI, MéxiCO, FCE, 2013, pp. 23-44.

${ }^{15}$ Esta visión es la que sostiene el autor de este trabajo en: Nuestra tragedia persistente. La democracia autoritaria en México, México, Debate, 2013. Véase también Mauricio Merino, El futuro que no tuvimos. Crónica del desencanto democrático, México, Planeta, 2012; Jo Tuckman, Mexico: Democracy Interrupted, New Haven, Yale University Press, 2012; Sergio Aguayo, Vuelta en U. Guía para entender y reactivar la democracia estancada, México, Taurus, 2010; y Víctor Alejandro Espinoza Valle y Alejandro Monsiváis (coords.), El deterioro de la democracia: consideraciones sobre el régimen político, lo público y la ciudadanía en México, Tijuana, El Colegio de la Frontera Norte, 2012.

${ }^{16}$ Véase la nota 1. 
EL ARRANQUE CONDICIONÓ EL FINAL

Es inevitable que el juicio político que se formule sobre el gobierno presidido por Calderón se haga en buena medida en función de su final y que este final se vea un tanto predeterminado por las circunstancias del desarreglo del inicio. Como sea, el cierre del sexenio 2006-2012 se caracterizó por lo siguiente. En primer lugar, por la derrota del partido gobernante, una derrota tan contundente que dejó al partido del presidente que salía en un tercer lugar con $25.4 \%$ del voto frente a $38.2 \%$ del candidato triunfante. Segundo, por la persistencia de la izquierda como fuerza significativa a pesar de sus claras divisiones: la coalición encabezada de nuevo en 2012 por López Obrador se desgajó, pero no antes de lograr 31.7\% del voto. Tercero, por la decisión de Calderón de hacer de la lucha contra y entre las organizaciones de narcotraficantes el núcleo duro de su política, lo que elevó notablemente los niveles de violencia -la cifra de muertes atribuida a este fenómeno en el sexenio se calculó, conservadoramente, en $64744^{17}$-, pero sin que tal costo lograra resolver el problema del crimen organizado en México, sino tan sólo transformarlo. ${ }^{18}$ Cuarto, por una derrota del PAN que no abrió la alternancia hacia la izquierda sino al retorno del PRI a la presidencia, es decir, que regresó al poder a la organización política identificada con el autoritarismo y la ambigüedad ideológica.

La elección del 1 de julio de 2006 se resolvió como la culminación de un enfrentamiento entre derecha e izquierda -PAN $v$ s. PRDy donde el PRI parecía destinado a desdibujarse. Sin embargo, el choque entre los antiguos opositores al PRI, y que en algunas ocasiones habían hecho frente común en nombre de la democracia, fue de tal naturaleza que desgarró y desvirtuó las aún débiles reglas de la contienda electoral y llevó al PAN a apoyarse en las organizaciones corporativas creadas por el PRI -el sindicato de maestros o el de trabajadores petroleros-y en el PRI mismo. Sin mayoría absoluta

${ }^{17}$ Cálculo de Andreas Schedler, "The Criminal Subversion of Mexican Democracy", Journal of Democracy, vol. 25, núm. 1, enero de 2014, p. 6.

18 Eduardo Guerrero Gutiérrez, "La raíz de la violencia”, Nexos, junio, 2011, pp. $30-45$. 
en el Congreso, el PAN requirió apoyo de los priistas y, en consecuencia, elementos centrales del viejo régimen encontraron el espacio para mantenerse vigentes. La decisión de las varias derechas mexicanas de cerrar por todos los medios a su alcance la posibilidad de que en 2006 la alternancia permitiera a la transición democrática marchar también por la izquierda, como ya lo había hecho en muchos otros países latinoamericanos y en la Península Ibérica, terminó por afectar la naturaleza misma del juego democrático.

Las consecuencias de las acusaciones de la izquierda en torno a un fraude electoral en 2006 y su negativa a aceptar no sólo la legitimidad de esa elección sino del sistema político mismo, hubieran podido revertirse o al menos neutralizarse si la autoridad electoral hubiera aceptado la demanda de la izquierda de un recuento de los votos -lo insignificante de la diferencia entre el ganador y quien le seguía lo justificaba-, pero la negativa tanto de los órganos electorales como del ganador, apoyado por el PRI, de llevar a cabo el recuento de los votos impidieron moderar la confrontación entre el ganador y perdedor. ${ }^{19}$ Años después, un análisis que empleaba sólo las actas de las casillas, pues nunca se autorizó la apertura de los paquetes electorales para el recuento, concluyó que lo reducido de la diferencia entre primer y segundo lugar y los naturales errores de conteo detectados y documentados, hacen materialmente imposible hasta la fecha determinar quién ganó realmente la elección del el 2 de julio de $2006 .{ }^{20}$ Para otro analista, Sergio Aguayo, en la elección de 2006 sí hubo fraude, pero no en su sentido tradicional como insistió López Obrador, sino uno diferente, "por agregación" de acciones no centralizadas de varios actores -el sindicato de maestros (SNTE), gobernadores o el Consejo Coordinador Empresarial-, y por negligencia del IFE. Los errores

${ }^{19}$ El Tribunal Electoral del Poder Judicial de la Federación reconoció la intervención ilegal tanto del presidente Vicente Fox como del Consejo Coordinador Empresarial en el desarrollo de la campaña electoral de 2006, pero finalmente concluyó que le era imposible determinar su impacto en el resultado final y, por lo tanto, sostuvo la validez del triunfo de Calderón. Instituto Federal Electoral, Elecciones Federales 2006, Justicia electoral, México, IFE, 2006, pp. 43,45 y 47.

${ }^{20}$ José Antonio Crespo, 2006, hablan las actas: las debilidades de la autoridad electoral mexicana, México, Random House-Mondadori, 2008. 
de López Obrador facilitaron que esas acciones ilegales concluyeran en la derrota de la izquierda. ${ }^{21}$

En cualquier caso, si bien el candidato del PRI se hundió en la irrelevancia, su partido no. El PRI se refugió en los gobiernos estatales que controlaba -donde el Estado de México resultó el más importante-, negoció su apoyo al gobierno de Calderón y explotó a fondo la debilidad del PAN para echar a andar un proyecto de recuperación del poder desde sus bastiones en la periferia, particularmente el Estado de México.

\section{EL PRINCIPIO}

La ceremonia de toma de protesta de Calderón como presidente el 1 de diciembre de 2006 se caracterizó por la protesta tumultuaria escenificada por la oposición en el Congreso y por la ausencia de cualquier rasgo de solemnidad. El panismo debió asumir su segunda presidencia con el apoyo de 17 gobiernos estatales de 32 y con una mayoría sólo relativa en la Cámara de Diputados $(42.2 \%)$ y en el Senado (40.6\%), por lo tanto el apoyo a Calderón de un PRI carente de compromisos ideológicos y sobrado de intereses sería la fórmula gobernante de 2006-2012: la negociación sistemática entre dos derechas con orígenes y estilos diferentes pero con intereses compatibles.

Tras la elección y después de asegurar en una entrevista que su triunfo, "haiga sido como haiga sido", era incuestionable, ${ }^{22}$ Felipe Calderón tomó una decisión que tuvo objetivos múltiples pero que, con el paso del tiempo, marcaría todo su sexenio: iniciar de inmediato -el 11 de diciembre de 2006- una acción militar de gran envergadura -“Operación Conjunta Michoacán” que movilizó a 5000 soldados, marinos y policías federales- para acabar con una organización de narcotraficantes -"La Familia Michoacana"- que ya domi-

${ }^{21}$ Aguayo, op. cit., pp. 191-230.

${ }^{22}$ La frase la pronunció Calderón en una entrevista televisada con la conductora Denise Maerker, tras la elección presidencial. En http://www.youtube.com/ watch?v=7hIqJlylLqw, consultado el 4 de abril de 2014 . 
naba territorialmente una parte importante de ese estado gobernado por el PRD y de donde era oriundo el flamante presidente. El objetivo evidente de la operación en Michoacán era responder de manera contundente a la evidente pérdida de control territorial del gobierno local y a la creciente ola de violencia desatada por el crimen organizado, que en ese año ya había cobrado 2500 vidas en el país. Hubo, además, dos razones adicionales para esta política de "mano dura". Por un lado, la presión norteamericana por duplicar en México el "Plan Colombia" y el propósito de ganar con el uso exitoso de la "fuerza legítima" el grado de legitimidad necesario para llevar a cabo otras políticas de fondo, como la privatización de la actividad petrolera y que el "mandato de las urnas" original no permitía. Por otro, la política de fuerza contra el crimen organizado permitiría señalar de manera indirecta al adversario político, la izquierda, que la tolerancia presidencial ante sus protestas y movilizaciones, como el ocupar por semanas la avenida Reforma en la ciudad de México, podía tener límites y contar con la fuerza para imponerlos. ${ }^{23}$

Desafortunadamente para Calderón y para la sociedad mexicana en su conjunto, la "guerra contra el narco", que luego dejó de calificarse así para pasar a ser sólo "campaña", no dio el resultado que esperaban los que la decidieron. La acción nunca fue bien pensada ni diseñada: predominó el uso de la fuerza por sobre el trabajo de inteligencia, lo espectacular sobre lo eficaz. (El 3 de enero de 2007, Calderón apareció semiuniformado como general de cinco estrellas en una base militar de Michoacán, situación sin precedentes en la historia política de México, donde los presidentes de origen militar solían quitarse el uniforme, incluido el general Victoriano Huerta, y los civiles no se lo ponían.) Para la segunda mitad del sexenio ya dominaba la sensación de fracaso del esfuerzo aunque la política se mantuvo invariable hasta el final. ${ }^{24}$ El enfoque

${ }^{23}$ Bertelsmann Foundation, Transformation Index, 2014, "Mexico Country Report”, Gütersloh, Bertelsmann Stiftung, 2014, p. 4.

${ }^{24}$ Las conclusiones adversas a la política de combate al narcotráfico son muchas. Un par de ejemplos son los trabajos de dos reporteros, uno mexicano y otro británico, que aparecieron en 2011. José Reveles, Levantones, narcofosas y falsos positivos, México, Grijalbo, 2011; Ioan Grillo, El narco: The Bloody Rise of Mexican Drug Cartels, Londres, Bloomsbury, 2011. 
que guio a esa "guerra contra el narco" coincidió o fue inspirado por el norteamericano, y consistió en centrarse en el ataque a la oferta, dejar en segundo plano a la demanda y en un tercero a las causas sociales que empujaban a miles de jóvenes de clase popular a nutrir las filas del crimen organizado. En 2008, el general secretario de Defensa calculó que alrededor de medio millón de mexicanos estaban involucrados de una forma u otra en la gran red de la economía del narcotráfico que funciona en un sistema de justicia totalmente inoperante y corrupto, donde $98 \%$ de las acciones criminales quedan en la impunidad. ${ }^{25}$

Como el enfoque de Calderón coincidió con el de Washington, no sorprendió el anuncio de la llamada "Iniciativa Mérida" en marzo de 2007. Se trató de un acuerdo (formalizado al año siguiente) entre los gobierno de México y Estados Unidos para definir el combate al narcotráfico como una "responsabilidad compartida", lo que implicaba una ayuda norteamericana a México en equipo y asesoría por 1490 millones de dólares en tres años -finalmente una suma muy menor comparada con el costo total que la empresa tendría para México-, pero que, sobre todo, implicó admitir como nunca antes la presencia de las agencias de seguridad norteamericanas en las mexicanas: policía federal, ejército, armada y sistema judicial. ${ }^{26}$ Sin embargo, a diferencia del caso colombiano, no se llegó a proponer que Estados Unidos desplegara unidades de su ejército en territorio mexicano.

$\mathrm{Al}$ concluir el sexenio calderonista, ni la "Iniciativa Mérida" ni el resto de la política contra los carteles de la droga pudieron calificarse de exitosos: 95\% de la cocaína consumida en Estados Unidos siguió pasando por México y los carteles mexicanos mantuvieron su posición como los principales proveedores externos de anfetaminas y marihuana de ese país, cuyo mercado de drogas al menudeo se supuso en 65000 millones de dólares anuales. ${ }^{27}$ Por lo que hace a los cálculos sobre el poder económico de los carteles mexicanos,

${ }^{25}$ Citado por Merino, op. cit., p. 186.

${ }^{26}$ Alma Arámbula Reyes, Iniciativa Mérida, compendio, México, Cámara de Diputados, LX Legislatura, 2008.

${ }^{27}$ Institute of Politics, "The War on Mexican Cartels. Options for U.S. and Mexican Policy-Makers”, Harvard University, 2012, p. 7. 
sus ingresos eran espectaculares: oscilaron entre 10000 y $40000 \mathrm{mi}$ llones de dólares anuales, y el principal narcotraficante mexicano de entonces, Joaquín "El Chapo" Guzmán Loera, apareció en la revista Forbes empatado con Emilio Azcárraga y Roberto Harp Helú entre el puñado de mexicanos poseedores de una fortuna superior a los mil millones de dólares. ${ }^{28}$ Un estudio elaborado en 2012 en Estados Unidos concluyó: "Pese a los esfuerzos de Estados Unidos de auxiliar a México en la Guerra contra las Drogas, la violencia va en aumento y los carteles siguen ganando terreno".29

A lo anterior debe añadirse el tema de las víctimas como parte central del costo mexicano de la guerra contra el narcotráfico: a los 64744 muertos ya citados hay que sumar los desaparecidos y desplazados más un aumento de la corrupción y la brutalización: torturas, desmembramientos, exhibición de cadáveres y ejecuciones colectivas que implicaron la degradación de la calidad de vida de los mexicanos al punto de que un estudio internacional colocó a México entre los países con mayores índices de violencia. ${ }^{30}$ El tema de la corrupción ligada al narcotráfico tuvo múltiples facetas, que lo mismo incluyeron las actividades de un hermano del gobernador de Michoacán, que un estudio de la Policía Federal que concluía que la totalidad de los 27 municipios de la zona de Tierra Caliente de ese estado estaban bajo control del crimen organizado. ${ }^{31}$ En el plano internacional la situación no fue mejor, en 2010 las autoridades norteamericanas impusieron multas por 160 millones de dólares a un banco de ese país controlado por Wells Fargo -el Wachovia Bank-, por haber permitido durante varios años operaciones que pudieron haber lavado dinero para el cartel de Sinaloa por un monto de ¡378400 millones de dólares! y que dejaron al banco infractor ganancias

${ }^{28}$ Forbes, 3 de noviembre de 2009.

${ }^{29}$ Institute of Politics, op. cit., p. 32.

${ }^{30}$ De acuerdo con el Índice Global de Paz publicado por el Institute for Economics and Peace en 2013, de 162 países examinados, México ocupaba la posición 133, http://www.visionofhumanity.org/pdf/gpi/2013_Global_Peace_Index_Report.pdf

${ }^{31}$ Estudio citado por El Universal, 30 de marzo de 2014. 
por 12300 millones de dólares. ${ }^{32}$ La red de complicidades con el narco era densa e internacional.

Ante el incremento en la violencia, el calderonismo fue notoriamente ineficaz e insensible en sus respuestas. En enero de 2010, por ejemplo, un grupo criminal asesinó en Ciudad Juárez a quince jóvenes reunidos en una celebración. La reacción presidencial consistió en atribuir de inmediato ese incidente, como ya lo había hecho con otros similares, a un ajuste de cuentas entre bandas criminales; sólo la respuesta airada de la sociedad juarense le obligó a retractarse y aceptar, finalmente, que las víctimas no tenían ningún nexo con criminales y que eran parte de la ola irracional de violencia que el Estado era incapaz de frenar. En un solo día -el 11 de junio de 2010- se registraron 77 asesinatos ligados al crimen organizado.

La "guerra contra el narcotráfico" pareció tener como objetivo central únicamente el descabezar a las grandes organizaciones criminales y disminuir así la magnitud del reto del mundo criminal al poder del Estado. Parte de este empeño consistió en entregar a las autoridades norteamericanas y desde el principio a "capos" importantes; apenas iniciado el sexenio, Osiel Cárdenas y Héctor "El Güero" Palma fueron extraditados, y a ellos seguirían más. La eliminación de Arturo Beltrán Leyva en 2009 y la captura el año siguiente de Édgar Valdez Villareal, "La Barbie”, no pudo ser coronada con la captura o eliminación del capo más importante de todos: Joaquín "El Chapo" Guzmán, cabeza del cartel de Sinaloa. Eso lo haría, con gran alarde de publicidad, el sucesor de Calderón, y ya no lo extraditaría.

Pese a la dureza de la campaña, los carteles no se replegaron ni disminuyeron el ritmo de su actividad, como lo muestran las cifras más adelante. ${ }^{33} \mathrm{Al}$ inicio de 2009, el cartel del Golfo asesinó a un general y unos meses después uno de sus comandos tomó un penal en Zacatecas; en 2010, un ataque con explosivos obligó a cerrar el consulado norteamericano en Nuevo Laredo; más tarde, en

32 The Guardian, 3 de abril de 2011, http://www.theguardian.com/world/ 2011/apr/03/us-bank-mexico-drug-gangs

${ }^{33}$ Véase la página 30. 
2011, un agente norteamericano del Servicio de Inmigración y Control de Aduanas fue asesinado en San Luis Potosí; y en agosto de 2012 agentes de la cia que entrenaban a marinos mexicanos y viajaban en un auto con placas diplomáticas fueron atacados en Morelos por policías federales mexicanos posiblemente al servicio del narcotráfico. ${ }^{34}$ Para entonces y en privado, Estados Unidos ya había perdido la confianza en la estrategia de Calderón y en su capacidad para llevarla a cabo, como lo evidenció la filtración de documentos diplomáticos norteamericanos por el sitio WikiLeaks los cuales permitieron al público saber que desde fines de 2009 la embajada norteamericana en México había considerado que la rivalidad entre las instituciones de seguridad, la corrupción y la aversión del ejército a asumir riesgos impedían la eficacia en las operaciones. ${ }^{35}$

Las diferencias sobre cómo manejar las acciones contra los carteles de la droga no fue el único motivo de tensión México-Estados Unidos en este ámbito. En México el gobierno y la opinión pública echaron en cara a Estados Unidos la poca eficacia de sus acciones en la disminución del consumo de drogas, de las medidas para impedir el lavado de dinero en sus bancos, y en materia de intercepción del flujo de armas hacia México. En la operación "Rápido y furioso”, el gobierno norteamericano dejó pasar ilegalmente 2500 armas a México para supuestamente rastrearlas después y averiguar la ruta que seguirían, pero al final perdió su rastro y algunas aparecieron en escenas de crímenes, incluido el de un agente norteamericano. ${ }^{36}$

No obstante lo anterior, la crítica de mayor fondo y efectividad a la política gubernamental -nacional y binacional- de combate a los carteles provino de la propia sociedad mexicana. En marzo de 2011, un grupo criminal asesinó al hijo del poeta Javier Sicilia y a otros seis jóvenes. En respuesta, Sicilia organizó una Marcha por la Paz con Justicia y Dignidad exigiendo al gobierno mexicano y al norteamericano -y al propio crimen organizado-detener la ola de

34 The New York Times, 28 de agosto de 2012.

${ }^{35}$ Véase al respecto a Andrea Conde Ghigliazza, "Cablegate. Las consecuencias diplomáticas de WikiLeaks en la relación bilateral México-Estados Unidos”, tesis de licenciatura, México, El Colegio de México, 2014.

36 Proceso, 29 de octubre de 2012. 
violencia extrema y sin sentido. Esa marcha se transformó rápidamente en un movimiento social (MPJD) que recorrió México y llegó hasta los Estados Unidos. La fuerza del MPJD que exigía un cambio de política más la reparación del daño a sus víctimas fue tal, que obligó a Calderón a crear una procuraduría especial (aunque la ley específica sobre el tema no llegó a aprobarse durante su gobierno) y a reunirse con Sicilia y otros miembros del movimiento para escuchar una crítica dura, irrebatible y pública a la política insignia del sexenio que había cobrado muchas vidas como "daños colaterales". ${ }^{37}$

Cuando Felipe Calderón entregó la presidencia a Peña Nieto en diciembre de 2012, había un consenso sobre el fracaso de la costosa y sangrienta campaña contra el crimen organizado en general y los carteles de la droga en específico. Es verdad que el "Plan Colombia" había tenido un éxito relativo en el país sudamericano, pero, irónicamente, a costa, entre otras cosas, de agudizar el problema en México. Los resultados de la "Iniciativa Mérida" no correspondieron, ni de lejos, con el esfuerzo y la cuota de sangre pagada ni con el daño hecho a la ya de por sí débil estructura institucional mexicana. ${ }^{38}$

\section{LO ECONÓMICO Y SOCIAL O LA POLÍTICA DE UN "BIEN COMÚN" QUE NO FUE TAN COMÚN}

En diciembre de 2006, la revista Forbes colocó al empresario mexicano Carlos Slim, cabeza del grupo Carso y magnate de las telecomunicaciones, como el tercer hombre más rico del mundo. Sin embargo, para final de sexenio, y por tercera vez, Slim apareció en la misma publicación ya como el hombre con la mayor fortuna del planeta: casi 70000 millones de dólares. Es decir que en seis años y pese al crecimiento más que mediocre de la economía mexicana

${ }^{37}$ Elena Azaola, "El Movimiento por la Paz con Justicia y Dignidad", Desacatos, núm. 40, septiembre-diciembre de 2012, pp. 159-170.

38 Bruce Bagley, "Tráfico de drogas y crimen organizado en las Américas: grandes tendencias en el siglo xxi”, en Abelardo Rodríguez Sumano (coord.), Agendas comunes y diferencias en la seguridad de América del Norte, México, Centro de Estudios Navales, 2012, p. 463. 
-en el sexenio calderonista, el crecimiento promedio anual del PIB per cápita fue de apenas un magro $0.91 \%{ }^{39}$-, el cuasi monopolista de las telecomunicaciones en México había más que duplicado el valor de su riqueza. La suma de lo acumulado ese año por Slim y por los otros diez mexicanos más acaudalados, sumó 129700 millones de dólares. ${ }^{40}$ En contraste, y de acuerdo con las cifras de la Comisión Económica para América Latina, en 2012 la proporción de la población mexicana clasificada como pobre fue de $37.1 \%$ y la de indigentes $14.2 \%$, o sea que en este campo la proporción también había aumentado, pues en 2006 había sido de 31.7 y $8.7 \%$ respectivamente. ${ }^{41}$ Si se toma la definición de política de Harold Lasswell -"quién consigue qué, cómo y cuándo" 42 - y se aplica a los procesos económicos y sociales, no hay duda de que la política real del gobierno de Calderón y el llamado "bien común" del ideario del PAN se encontraron en polos opuestos; el "bien" se reservó a los muy pocos y para el "común" sólo quedo el estancamiento o de plano el retroceso.

El "Programa Oportunidades" - un programa de transferencia de ingresos a familias pobres, sobre todo rurales, en beneficio de los niños y que favoreció a cinco millones de familias-y el resto de la gama de programas gubernamentales para disminuir la pobreza, si bien llevaron a que el impacto de la desigualdad no fuera tan brutal como lo hubiera sido si se hubiera dejado operar sin interferencia a las fuerzas del mercado, finalmente no cambiaron la realidad de los pobres. Es verdad que la proporción del ingreso disponible para el $20 \%$ más pobre de la población pasó de representar $5.9 \%$ en 2002 a $6.6 \%$ en $2012,{ }^{43}$ pero también es cierto que

${ }^{39}$ Naciones Unidas, Comisión Económica para América Latina y el Caribe, “Anuario Estadístico 2013”, http://interwp.cepal.org/anuario_estadistico/anuario_2013/es/index.asp, consultado el 2 de julio de 2014.

${ }^{40}$ Datos proporcionados por la revista Forbes.

${ }^{41}$ Naciones Unidas, Comisión Económica para América Latina y el Caribe, Panorama social de América Latina, 2013, Santiago de Chile, 2013, p. 19.

42 Harold D. Lasswell, Politics: Who Gets What When and How, Nueva York, Meridian Books, 1958.

${ }^{43}$ Naciones Unidas, Comisión Económica Para América Latina y El Caribe, op. cit., p. 17. 
al concluir el sexenio bajo análisis México resultó ser el único país latinoamericano en donde los indicadores de pobreza, en vez de disminuir, aumentaron, si bien ligeramente. ${ }^{44}$ Un análisis comparativo entre el primer y segundo sexenio panistas que tomó en cuenta la estructura de clase y los ingresos mostró que la ligera mejora en ingresos y disminución de la desigualdad durante el sexenio de Fox se perdió en el de Calderón como resultado del bajo crecimiento, y que lo poco que hubo de redistribución se dio dentro de los estratos altos sin modificar la desigualdad del conjunto. ${ }^{45}$

La evolución de México en materia de pobreza y desigualdad en el sexenio 2006-2012 no se puede separar de otros fenómenos igualmente significativos en el periodo, como fueron la política laboral o la evolución del flujo migratorio. Del ingreso disponible total, resulta que la parte correspondiente a la remuneración al trabajo fue equivalente a poco menos de la mitad de aquella que logró el capital. Esta tendencia desfavorable a los asalariados no fue privativa de México, sino un fenómeno bastante extendido y asociado, en parte, al modelo económico y en parte al debilitamiento numérico y político de los sindicatos. Durante el periodo examinado, la política hacia los sindicatos mostró dos caras opuestas, una muy dura y otra extremadamente complaciente. La dura la ejemplifica la disolución, empleando incluso la fuerza, de la vieja empresa Luz y Fuerza del Centro en 2009, lo que representó un golpe mortal para uno de los sindicatos de mayor tradición en México, el Sindicato Mexicano de Electricistas (SME), creado en 1914, y que afectó a más de 44000 trabajadores. En contraste, la relación del gobierno de Felipe Calderón con el mayor sindicato de América Latina, el Sindicato Nacional de Trabajadores de la Educación (SNTE), encabezado por Elba Esther Gordillo -más de un millón de agremiados-, fue de apoyo mutuo. Al snte, Calderón le dio posiciones clave dentro de la estructura gubernamental, al

${ }^{44}$ Naciones Unidas, Comisión Económica Para América Latina y El Caribe, op. cit., p. 19.

${ }^{45}$ Patricio Solís y Gabriela Benza, "Classes sociales, pauvreté et inégalités dans les annés de la alternance presidentielle”, en Problèmes d'Amerique latine. Mexique 2000-2012, limites et impasses de la transition démocratique, núm. 89, 2013, pp. 33-53. 
punto de que en 2009 se calculó que el grupo dirigente del SNTE manejó recursos provenientes directa o indirectamente del erario, por 384982 millones de pesos anuales. ${ }^{46}$ Esta diferencia en el trato se debió a que la movilización del sNTE en favor de Calderón fue vista por éste como crucial para que ganara la elección en 2006 y la del sMe no.

Al final del gobierno calderonista, el ejecutivo logró que el legislativo aprobara una modificación profunda de la Ley Federal del Trabajo, modificación apoyada ya por el presidente electo, Enrique Peña Nieto. Esta reforma "flexibilizó" las condiciones de contratación y despido de los trabajadores y permitió los contratos por hora. La reforma fue muy bien recibida por el sector empresarial, pero no por los sindicatos, que vieron disminuir la protección al trabajo en nombre de una promesa de mayor creación de plazas en el empleo formal, promesa que hasta el momento de escribir estas líneas no se ha cumplido.

En la realidad, la reforma laboral simplemente legalizó lo que ya se venía practicando de tiempo atrás en México y en muchos otros países en aras de mantener a cada país "competitivo" en el mercado global. Ahora bien, como la gran mayoría de los trabajadores mexicanos laboraban en el mercado informal y en las pequeñas empresas, para ellos el cambio no fue significativo y la relevancia de la globalización y sus supuestas ventajas resultó muy relativa. El salario mínimo siguió dentro de la tendencia establecida a partir de la crisis de 1982: perdiendo poder adquisitivo. ${ }^{47}$ Para 2010 se calculó que $44.3 \%$ de los asalariados mexicanos percibían menos de dos salarios mínimos, cuando, de haberse cumplido el requerimiento constitucional de proveer al trabajador con un salario mínimo para cubrir de manera adecuada las necesidades "normales de un jefe de familia, en el orden material, social

${ }^{46}$ Se trata de los presupuestos de seis dependencias oficiales que estaban bajo la influencia del SNTE: el propio SNTE, la SEP, el ISSSTE, la lotería, el sistema de seguridad pública y el Partido Nueva Alianza. Cálculo de Sergio Aguayo, Remolino. El México de la sociedad organizada, los poderes fácticos y Enrique Peña Nieto, libro electrónico, México, Sextil Online, 2014, p. 143.

${ }^{47} \mathrm{Si}$ en el año 2000 un salario mínimo podía adquirir 8 kilos de tortillas, en 2011 sólo podía acceder a 5 . 
y cultural", ${ }^{48}$ se hubiera requerido de al menos una suma cuatro veces mayor. ${ }^{49}$

La gran recesión mundial que estalló en 2008 a raíz de los manejos especulativos del sector financiero norteamericano golpeó de manera directa a México por su liga tan estrecha con el mercado norteamericano, producto del Tratado de Libre Comercio de la América del Norte suscrito en 1993. Por eso, el crecimiento anual promedio del PIB entre 2007 y 2012 fue de apenas $2.1 \%,{ }^{50}$ lo que significó, como ya se apuntó, que el crecimiento per cápita no llegara ni a 1\%, cifra absolutamente insuficiente para generar el empleo demandado por el ingreso anual promedio de un millón de jóvenes al mercado de trabajo. De ahí la importancia, como válvula de escape a la presión laboral, tanto del crimen organizado por un lado como de la migración de trabajadores mexicanos a Estados Unidos, por otro. En 2009 se calculó que anualmente en 5.4 de cada mil mexicanos migraban, aunque la proporción disminuyó a 3.3 en 2012, pero no porque hubiera mejores oportunidades en México, sino por las dificultades crecientes de los migrantes para cruzar la frontera y conseguir trabajo en unos Estados Unidos con serias dificultades económicas a partir de 2008.51 En cualquier caso, para 2012 había 11.9 millones de migrantes mexicanos en Estados Unidos, ${ }^{52}$ es decir que $10 \%$ de México se localizaba fuera de sus fronteras.

Como ya se advirtió, el grueso del empleo creado en el sexenio de Calderón -55.3\% - no se dio en el sector dinámico y exportador,

${ }^{48}$ Artículo 123 constitucional, apartado VI.

${ }^{49}$ Miguel Santiago Reyes H., "Los salarios en México", Análisis político, México, Frierdrich Ebert Stiftung, noviembre de 2011, pp. 22-23.

${ }^{50}$ Véase la nota 39.

${ }^{51}$ Instituto Nacional de Estadística, Geografía e Informática, Principales resultados del censo de población y vivienda, 2010, México, INEgI, p. 25; Migration Policy Institute, "Frequently Requested Statistics on Immigrants and Immigration in the United States", http:/ /www.migrationpolicy.org/article/frequently-requestedstatistics-immigrants-and-immigration-united-states\#3, consultado el 19 de abril de 2014.

${ }^{52}$ Fundación biva Bancomer, Anuario de migración y remesas, México 2013, México, Fundación ввva Bancomer, 2012, p. 42. 
sino en el informal y menos productivo. ${ }^{53}$ Obviamente, ninguna de las características de la estructura social mexicana mencionadas desigualdad, pobreza, debilitamiento del sindicalismo, expulsión de población hacia Estado Unidos, precariedad del empleo y otras similares- surgieron en el sexenio de Calderón; venían de atrás. Lo significativo del periodo es que el esfuerzo se centró en mantener baja la tasa de inflación y no hubo ningún esfuerzo significativo para revertir los procesos mencionados; hacia ellos la política consistió básicamente en administrarlos.

Para los observadores, el México del final de la primera década del siglo xxi era una sociedad donde la desigualdad y la pobreza se podían considerar características estructurales y que correspondían a un modelo económico centrado en las exportaciones y que por tres decenios consecutivos había descuidado el mercado interno. Sin modificar el modelo, la situación permanecería básicamente igual. ${ }^{54}$

\section{LA REFORMA PETROLERA}

Dentro del proyecto neoliberal echado a andar a mediados de los ochenta, un punto central fue la privatización de las grandes empresas estatales. Para inicios del siglo xxi, el único sector industrial importante que faltaba por pasar de manos estatales a las privadas era el energético. Se argumentaba, de muchas formas y en foros nacionales y extranjeros, que era justamente la falta de esa reforma -la joya de la política privatizadora- lo que había frenado el crecimiento de una economía que ya era, básicamente, de libre mercado. En consecuencia, el gobierno de Calderón desarrolló en 2008 una gran campaña de publicidad como etapa previa para hacer realidad la reforma constitucional del artículo 27 y que abriera a las empresas estatales-PEMEx y la Comisión Federal de Electricidad-a la inversión privada como única forma de proceder a explotar los

53 Cálculo del Centro de Análisis Multidisciplinario de la UNAM, Reporte 95, citado por La Jornada, 19 de abril de 2012.

${ }^{54}$ Bertelsmann Foundation, op. cit., p. 22. 
grandes depósitos petroleros -“el tesoro" se le llamó en los spots del gobierno en prensa, radio y televisión- que se encontraban en las aguas profundas del Golfo de México. ${ }^{55}$

La idea de una gran alianza neoliberal PAN-PRI para llevar a cabo el cambio histórico en el marco legal del petróleo era plausible, pero finalmente el PRI no la apoyó y el PRD, bajo el liderazgo de López Obrador, llevó a cabo una movilización que terminó por echar por tierra el proyecto de Calderón; en cambio, se aceptó que PEMEX procediera a construir nuevas refinerías -lo que no se hacía en los últimos 35 años- para no seguir exportando petróleo crudo e importando refinados. La renuencia del PRI a secundar entonces la reforma constitucional energética tendría su explicación unos años más adelante, cuando en 2013 y ya en la presidencia el PRI sí consiguió negociar la reforma, en sus propios términos con un PAN ya debilitado. Por su parte, Calderón puso tan poco interés en la construcción de la nueva refinería en Tula, Hidalgo, en la que supuestamente se debería invertir 10000 millones de dólares, que al concluir su mandato apenas se había construido la barda del terreno. En suma, el activismo del PRD y la indiferencia del PRI echaron por tierra el proyecto de reforma petrolera de Calderón, pero la inactividad del Ejecutivo en materia de refinerías también echó por tierra el proyecto alternativo de la izquierda. El resultado final en esta materia fue la victoria del statu quo.

\section{LA DISPERSIÓN DEL PODER}

Una característica del sistema político mexicano durante la larga etapa de monopolización de la presidencia por el grupo que reconstruyó el sistema una vez concluida la Revolución mexicana, fue la centralización de ese poder en manos del presidente, en especial a partir del gobierno del presidente Lázaro Cárdenas y de la transformación del partido oficial de uno de cuadros a uno de masas. ${ }^{56}$

${ }^{55}$ La Jornada, 20 de abril y 4 de julio de 2008.

56 Véase Arnaldo Córdova, La política de masas del cardenismo, México, ERA, 1974; también: Luis Javier Garrido, El partido de la revolución institucionalizada: 
El presidencialismo mexicano del siglo xx se basó en la amalgama de sus poderes constitucionales con los meta constitucionales ${ }^{57}$-jefe indiscutible del partido de Estado y por esa vía de los gobernadores, de los gobiernos municipales, del poder legislativo y del judicial-y con una serie de poderes anticonstitucionales o francamente ilegales: control de los medios de comunicación, violación impune de los derechos humanos o tráfico de influencias, entre otros. ${ }^{58}$

Con la pérdida de poder presidencial en la última etapa del PRI y con la salida de ese partido de Los Pinos en 2000, el sistema político mexicano experimentó una notable dispersión del poder, aunque el pluralismo resultante -una peculiar poliarquía- no necesariamente transformó en una democracia de calidad al nuevo sistema. ${ }^{59}$

Con el paso del tiempo, Calderón, como su antecesor, tuvo que gobernar con una mayoría de gobernadores y el jefe de gobierno en la capital de oposición -25 de 32 en 2008-, y lo mismo le sucedió con respecto a los legisladores federales y locales. Conseguir el apoyo o al menos la coordinación con los gobernadores de oposición -mayoritariamente priistas- para llevar adelante políticas concretas no le fue fácil y en ocasiones simplemente le resultó imposible, lo que en parte explica el fracaso de muchas acciones contra el crimen organizado o las dificultades de controlar el gasto público o el endeudamiento irresponsable o francamente corrupto de los estados -el ejemplo extremo fue Coahuila-, que emplearon esa

medio siglo de poder en México, la formación del nuevo Estado (1928-1945), México, SEP, 1986.

${ }^{57}$ Jorge Carpizo, El presidencialismo mexicano, México, Siglo XXI, 2006.

${ }^{58}$ Un ejemplo de este poder presidencial francamente ilegal en los años cuarenta se expone en: Stephen R. Niblo, Mexico in the 1940's: Modernity, Politics and Corruption, Wilmington, Del., Scholarly Resources, 1999. Otro ejemplo, posterior, relacionado con la represión y el asesinato, se tiene en Carlos Monsiváis y Julio Scherer, Parte de guerra: Tlatelolco 1968. Documentos del general Marcelino García Barragán. Los hechos y la historia, México, Aguilar, 1999.

${ }^{59} \mathrm{El}$ surgimiento de los gobernadores como auténticos poderes locales a costa del poder presidencial es el tema de la obra de Rogelio Hernández, El centro dividido: la nueva autonomía de los gobernadores, México, El Colegio de México, 2008. 
deuda más en gasto corriente sin supervisión y mucho menos en inversión. ${ }^{60}$

Un buen número de eventos y procesos políticos del calderonismo se explicaron mediante el uso del concepto de "poderes fácticos". ${ }^{61}$ Para Alberto Olvera, estos poderes han resultado la parte central de una "sociedad incivil", los cuales, en la práctica, distorsionaron la transición democrática mexicana hasta frustrarla. Se trató, básicamente, de actores privados que de hecho asumieron funciones estatales; intereses creados y bien organizados durante la larga etapa autoritaria que se propusieron usar sus recursos políticos y económicos, legales e ilegales, para mantener o aumentar su extracción de renta a costa de frustrar el cambio de fondo. El núcleo duro de estos poderes fácticos lo constituyeron "los grandes sindicatos corporativos, los caciques regionales, las empresas monopólicas y, más recientemente, el crimen organizado". ${ }^{62}$ Olvera les pone nombre y apellido a estos poderes que limitaron no sólo la capacidad de actuar del presidente sino del sistema político en su conjunto: se trató de los grandes sindicatos corporativos de maestros, trabajadores petroleros y de otras áreas del gobierno federal, Telmex y Telcel, las dos grandes cadenas de televisión (Televisa y tv Azteca), Cemex, los cinco bancos mayores que controlan $80 \%$ de su mercado, los carteles del narcotráfico, particularmente el de Sinaloa, y ciertos caciques regionales.

Los partidos políticos fueron otro poder notable, al punto que para finales del primer decenio del siglo xxi México se podía definir más como partidocracia que como democracia. Las encuestas mostraron que la opinión pública tenía cada vez en menos estima

${ }^{60}$ México Evalúa, Centro de Análisis de Políticas Públicas, "Gasto y deuda pública estatal ¿para qué?”, http:/ / www.mexicoevalua.org/wp-content/uploads/2013/ 07/Gasto-y-deuda-p\%C3\%BAblica-en-las-entidades-federativas_Mexico-Evaluajul2013-vf.pdf, consultado el 20 de abril de 2014.

61 Aguayo, op. cit., pp. 130-176.

62 Alberto Olvera, "Poderes fácticos y democracia en México: sindicatos, caciques, monopolios y delincuencia organizada en un país en transición”, en Isidoro Cheresky (comp.), Ciudadanía y legitimidad democrática en América Latina, Buenos Aires, Prometeo, 2011, pp. 311-337. 
al sistema de partidos, ${ }^{63}$ pero los ciudadanos simplemente no tuvieron forma de impedir que organizaciones tan poco representativas absorbieran cantidades desproporcionadas y cada vez mayores de recursos públicos y fueran nidos de individuos que vivían más de la política que para la política. En 2012, el monto del financiamiento público a los siete partidos políticos con registro llegó a los 5142.5 millones de pesos. ${ }^{64}$ Así, instituciones a las que menos de una quinta parte de la ciudadanía consideraba que cumplían su papel de representantes de los intereses sociales mayoritarios, reafirmaron su carácter de exitosos entes políticos si nos atenemos a la ya citada definición de política: "quién consigue qué [cantidad de dineros públicos], cómo y cuándo”.

\section{FinALMENTE, LA CORRUPCióN}

El PAN, desde su origen como partido de oposición, se propuso subrayar que la corrupción en el campo de la política era una de las grandes trabas al desarrollo material y político de México. Al asumir el poder en el año 2000, se supuso que Vicente Fox iniciaría el combate contra este mal endémico y al que se ligaba con la ausencia de rendición de cuentas durante la larga etapa del autoritarismo priista. Finalmente, Fox nunca capturó a ninguno de los "peces grandes" de la corrupción, como había prometido, y la situación no cambió durante la presidencia de Felipe Calderón.

Los índices de corrupción son instrumentos de medición cuantitativa muy crudos, pero no hay otros mejores. Transparencia Internacional le dio a México en 2007 un puntaje de 35 sobre 100 en

${ }^{63}$ En 2013 apenas 19\% de los ciudadanos dijo tener confianza en los partidos políticos. Es de notar que en una encuesta similar en 2010 la cifra reportada fue de $35 \%$, lo que significa una caída notable durante el calderonismo. Instituto Federal Electoral, Informe país sobre la calidad de la ciudadanía en México, México, IFE, 2014, p. 128.

${ }^{64}$ Cifras del Instituto Federal Electoral, http://www.ife.org.mx/docs/IFE-v2/ DEPPP/PartidosPoliticosyFinanciamiento/DEPPP-financiamiento/financiamientopublicopartidosnacionales/financiamientopublico1997-2014.pdf, consultado 2 de julio 2014. 
el índice de percepción del grado de corrupción; seis años más tarde, en el informe de 2013, la situación era igual: el índice fue de 34 sobre cien, pero si en el primer caso México quedó colocado en el lugar 72 de un total de 179 países -el último lugar lo ocupó el país con el peor nivel-, en el segundo descendió al 106. ${ }^{65}$ Obviamente un problema tan arraigado y complejo como es el de la corrupción no puede resolverse en un sexenio, pero en los seis años de calderonismo no se percibió ningún esfuerzo en ese sentido. Un área tan susceptible a ser vista como indicador de voluntad o símbolo de combate o de tolerancia del poder público frente a la corrupción como es la industria petrolera, fue presentada por el periodismo de investigación como ejemplo casi perfecto del tráfico de influencias y del abuso de poder en beneficio de particulares durante las dos administraciones panistas. ${ }^{66}$ En suma, en una encuesta hecha por la Secretaría de Gobernación y publicada en 2012, una muestra representativa de ciudadanos dio al país un puntaje de 4.54 en una escala de cero a cinco, donde cero significaba la ausencia de corrupción y cinco la corrupción total. El 43\% de los encuestados consideró que sí era posible acabar con esa corrupción en tanto que $56 \%$ vio tamaña empresa como algo poco o nada posible. ${ }^{67} \mathrm{Al}$ dejar el PAN Los Pinos, la moral pública estaba por los suelos.

\section{PARA CONCLUIR}

El gobierno presidido por Felipe Calderón cerró el relativamente breve intervalo de la alternancia de partidos en el poder en México. El retorno a la presidencia del partido que monopolizó el poder por casi todo el siglo xx -el PRI- encontró a un México con una ciudadanía más participativa, más consciente de sus derechos que en la época del autoritarismo clásico, pero que aún estaba

65 Fuente: Transparencia Internacional, http://www.transparency.org/research/cpi/cpi_2007 y http:/ / cpi.transparency.org/cpi2013

66 Ana Lilia Pérez, Camisas azules, manos negras. El saqueo de Pemex desde Los Pinos, México, Grijalbo, 2010.

${ }^{67}$ Fuente: Secretaría de Gobernación, Encuesta nacional sobre cultura política y prácticas ciudadanas, ENCUP, 2012, http://www.encup.gob.mx 
lejos de constituir una sociedad civil vigorosa y comprometida con la democracia. ${ }^{68}$ La forma en que Calderón y el PAN y sus apoyos ganaron la presidencia en 2006 y ejercieron sus atribuciones no contribuyó a la consolidación de una democracia que en México no tenía antecedentes históricos significativos y que, por tanto, aún necesitaba tiempo para arraigar y madurar. El calderonismo no logró superar en las elecciones intermedias su carácter de gobierno minoritario, tampoco pudo dar forma a un proyecto político que despertara la imaginación del público ni, menos, recuperar o aumentar la confianza de los ciudadanos en el entramado institucional.

El PRI al que Felipe Calderón entregó la presidencia en 2012 dijo ser un partido renovado, distinto del que sirvió de instrumento al presidencialismo autoritario que emergió de la Revolución mexicana, pero en realidad ninguna de sus viejas características antidemocráticas desapareció durante los doce años en que actuó como oposición. El retorno del poder presidencial a manos del PRI se debió menos al respaldo vigoroso de la ciudadanía a ese viejo partido y más al fracaso del panismo, que se empeñó en confrontar con todos los medios disponibles la posibilidad de una alternancia hacia la izquierda, y facilitó el retorno de lo que le era más cercano: la "derecha antigua", la priista.

\section{BibLIOGRAFÍA}

Aguayo, Sergio, Vuelta en U. Guía para entender y reactivar la democracia estancada, México, Taurus, 2010.

——, Remolino. El México de la sociedad organizada, los poderes fácticos y Enrique Peña Nieto, libro electrónico, México, Sextil Online, 2014.

Aguilar Camín, Héctor y Jorge G. Castañeda, Un futuro para México, México, Punto de Lectura, 2009. - Una agenda para México, México, Punto de lectura, 2012.

${ }^{68}$ De acuerdo con los resultados de la encuesta de Latinobarómetro de 2013, en México el apoyo a las formas democráticas de gobierno había disminuido en $3 \%$ desde 2011 y, en cualquier caso, no era mayoritaria (37\%). 
Arámbula Reyes, Alma, Iniciativa Mérida, compendio, México, Cámara de Diputados, LX Legislatura, 2008.

Azaola, Elena, "El Movimiento por la Paz con Justicia y Dignidad", Desacatos, núm. 40, septiembre-diciembre de 2012.

Bagley, Bruce, "Tráfico de drogas y crimen organizado en las Américas: grandes tendencias en el siglo xxı", en Abelardo Rodríguez Sumano (coord.), Agendas comunes y diferencias en la seguridad de América del Norte, México, Centro de Estudios Navales, 2012.

Bertelsmann Foundation, Transformation Index, 2014, "Mexico Country Report”, Gütersloh, Bertelsmann Stiftung, 2014.

Carpizo, Jorge, El presidencialismo mexicano, México, Siglo XXI, 2006.

Conde Ghigliazza, Andrea, "Cablegate. Las consecuencias diplomáticas de WikiLeaks en la relación bilateral México-Estados Unidos”, tesis de licenciatura, México, El Colegio de México, 2014.

Córdova, Arnaldo, La política de masas del cardenismo, México, ERA, 1974.

Crespo, José Antonio, 2006, hablan las actas: las debilidades de la autoridad electoral mexicana, México, Random House-Mondadori, 2008.

Cuéllar, Angélica y Roberto Oseguera, El desafuero de Andrés Manuel López Obrador, México, Guernika, 2011.

Espinoza Valle, Víctor Alejandro y Alejandro Monsiváis (coords.), El deterioro de la democracia: consideraciones sobre el régimen político, lo público y la ciudadanía en México, Tijuana, El Colegio de la Frontera Norte, 2012.

Fundación bвva Bancomer, Anuario de migración y remesas, México 2013, México, Fundación вbva Bancomer, 2012.

Garrido, Luis Javier, El partido de la revolución institucionalizada: medio siglo de poder en México, la formación del nuevo estado, (1928-1945), México, SEP, 1986.

Grillo, Ioan, El narco: The Bloody Rise of Mexican Drug Cartels, Londres, Bloomsbury, 2011.

Guerrero Gutiérrez, Eduardo, "La raíz de la violencia”, Nexos, junio, 2011. Hernández, Rogelio, El centro dividido: la nueva autonomía de los gobernadores, México, El Colegio de México, 2008.

Institute for Economics and Peace, Índice Global de Paz, 2013, http:// www.visionofhumanity.org/pdf/gpi/2013_Global_Peace_Index_Re port.pdf

Institute of Politics, "The War on Mexican Cartels. Options for U.S. and Mexican Policy-Makers", Cambridge, Harvard University, 2012. 
Instituto Federal Electoral, Informe país sobre la calidad de la ciudadanía en México, México, IFE, 2014. , Elecciones Federales 2006, Justicia electoral, México, IFE, 2006.

Instituto Nacional de Estadística, Geografía e Informática, Principales resultados del censo de población y vivienda, 2010, México, INEGI.

Lasswell, Harold D., Politics: Who Gets What When and How, Nueva York, Meridian Books, 1958.

Merino, Mauricio, El futuro que no tuvimos. Crónica del desencanto democrático, México, Planeta, 2012.

México Evalúa, Centro de Análisis de Políticas Públicas, "Gasto y deuda pública estatal ¿para qué?”, http://www.mexicoevalua.org/wp-content/uploads / 2013/07/Gasto-y-deuda-p\% C3\%BAblica-en-las-entidades-federativas_Mexico-Evalua-jul2013-vf.pdf

Meyer, Lorenzo, Nuestra tragedia persistente. La democracia autoritaria en México, México, Debate, 2013.

Migration Policy Institute, "Frequently Requested Statistics on Immigrants and Immigration in the United States", http:/ /www.migrationpolicy. org/article/frequently-requested-statistics-immigrants-and-immigra tion-united-states\#3

Modoux, Magali, "Geografía de la gobernanza. ¿La alternancia partidaria como factor de consolidación del poder de los gobernadores en el escenario nacional?”, Foro Internacional, vol. 46, núm. 3, 2006.

Monsiváis, Carlos y Julio Scherer, Parte de guerra: Tlatelolco 1968. Documentos del general Marcelino García Barragán. Los hechos y la historia, México, Aguilar, 1999.

Moreno, Alejandro, "La desconfianza electoral en México”, Este Pais, marzo de 2014.

Naciones Unidas, Comisión Económica para América Latina y el Caribe, “Anuario Estadístico 2013”, http://interwp.cepal.org/anuario_estadistico/anuario_2013/es/index.asp

—, Panorama social de América Latina, 2013, Santiago de Chile, 2013.

Niblo, Stephen R., Mexico in the 1940's: Modernity, Politics and Corruption, Wilmington, Del., Scholarly Resources, 1999.

Olvera, Alberto, "Poderes fácticos y democracia en México: sindicatos, caciques, monopolios y delincuencia organizada en un país en transición”, en Isidoro Cheresky (comp.), Ciudadanía y legitimidad democrática en América Latina, Buenos Aires, Prometeo, 2011. 
Pérez, Ana Lilia, Camisas azules, manos negras. El saqueo de Pemex desde Los Pinos, México, Grijalbo, 2010.

Reveles, José, Levantones, narcofosas y falsos positivos, México, Grijalbo, 2011.

Reyes H., Miguel Santiago, "Los salarios en México", Análisis político, México, Friedrich Ebert Stiftung, noviembre de 2011.

Schedler, Andreas, "The Criminal Subversion of Mexican Democracy", Journal of Democracy, vol. 25, núm. 1, enero de 2014.

Secretaría de Gobernación, Encuesta nacional sobre cultura política y prácticas ciudadanas, ENCUP, 2012, http://www.encup.gob.mx

Solís, Patricio y Gabriela Benza, "Classes sociales, pauvreté et inégalités dans les annés de la alternance presidentielle", en Problèmes d'Amerique latine. Mexique 2000-2012, limites et impasses de la transition démocratique, núm. 89, 2013, pp. 33-53.

Tuckman, Jo, Mexico: Democracy Interrupted, New Haven, Yale University Press, 2012.

Woldenberg, José, Historia mínima de la transición democrática en México, México, El Colegio de México, 2012.

—_ "Los déficits de la transición democrática”, en José Ramón Cossío y Enrique Florescano (coords.), La perspectiva mexicana en el siglo XXI, México, FCE, 2013.

Periódicos y revistas

El Universal

Forbes

La Jornada

Proceso

Reforma

The Guardian

The New York Times 